\title{
Career pathways, part 5
}

\author{
In this instalment of Career pathways, Kivanç Birsoy and Sarah Lessard recount their roads to scientific research \\ and reflect on how each step in their training prepared them for life as a group leader.
}

\section{Kivanc Birsoy and Sarah J. Lessard}

\section{Kivanç Birsoy: learning the ropes}

I did not make a deliberate plan to study biology at a young age. In fact, running a lab in America was not something I ever dreamed of. In 1980s postcoup Turkey, most parents wanted their children to make safe life decisions, such as becoming a physician. That was the path I was supposed to follow. Instead, I went to a public science boarding school, where I fell in love with science. I was not exactly sure what I wanted to do at the time, but I had a sense that genetics was going to have a big impact on the future of research. With that, I decided to pursue my bachelor's degree at Bilkent University, one of the few universities at the time with a molecular genetics program in Turkey.

I knew that I wanted more experience doing bench science. On my own initiative, I spent my summers during college working in various labs in the United States, mostly as a result of cold-contacting the investigators in labs whose research I found interesting. It was during this time that I truly appreciated the need to do science in the United States. In 2005, during my internships, I had become more and more interested in metabolism, and so when it came time to start my $\mathrm{PhD}$, I joined the lab of Jeff Friedman, who is still a mentor to me and among the most generous scientists I know. He gave me the freedom to explore any subject I wanted during my $\mathrm{PhD}$, which allowed me to develop my own research direction. Although I enjoyed the wealth of biological questions in the metabolism field, I was also frustrated by the lack of unbiased genetic tools to study cellular metabolism.

At the time of my PhD, David Sabatini's lab was pioneering the development of new technologies to facilitate the analysis of gene function in mammalian cells. For my postdoctoral work, I joined his lab with a hope to further develop these robust functional genomics techniques and apply them to the study of metabolism. Through the years, we used these tools to understand how cellular metabolism, especially that of cancer cells, responds to environmental stresses. David had the unique ability to create a lab environment full of talented scientists with various areas of expertise,

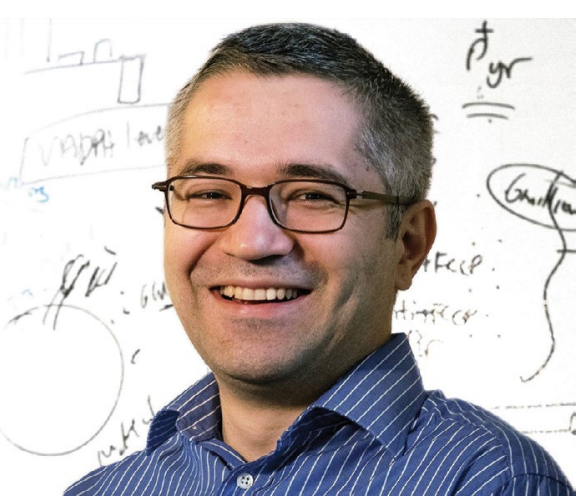

Credit: The Rockefeller University

which provided an amazing resource for me. After my long training, struggle with immigration and multiple security checks, the Birsoy lab finally opened at the Rockefeller University 5 years ago.

I was lucky that I returned to my graduate school as a faculty member. Although this made the transition relatively easy, I still remember how nervous I was in a completely empty lab with unopened boxes and brand-new equipment. To calm myself down, I was constantly reaching out to senior colleagues in my institution and other junior faculty friends to ask for their input, which was very helpful. In the beginning, I took the advice of several colleagues and waited for some time to hire the people who best fit with my personality and interests. This was probably some of the best advice I received, in addition to the advice to stay in an apartment close to the lab. Despite being in an empty lab for several weeks, I actually found this period quite useful. I took my time to write grants, think about potential future directions and continually read the old literature to find unanswered biological questions in the metabolism field.

The scientific questions that we ask in my lab are motivated by a fascination by how metabolic pathways are altered in the disease states. Yeast has historically been the model organism to study eukaryotic metabolism, because of its relative ease of gene manipulation. Although certain aspects of human cell metabolism resemble that of yeast, human cells display highly complex and specialized, but also redundant, metabolic functions. To overcome this challenge, we apply high-throughput gene-editing tools based on CRISPR to answer numerous questions in the metabolism field. This unique approach has allowed us and many others to study how metabolic pathways in human cells are regulated under environmental stresses.

Several years ago, while studying the metabolism of cancer cells, we also realized that we could use this expertise to identify metabolic genes whose functional identities are undefined. To start such a fishing expedition, a postdoc and a graduate student in my lab decided to use a genetic coessentiality approach focusing on metabolism genes. In collaboration with Sumanta Basu's lab at Cornell, we constructed a metabolic network using coessentialities of more than 500 cancer cell lines from a database of functional genetic screens (DepMap) and assigned metabolic functions to several unknown genes. In particular, we identified that C12orf49, an uncharacterized gene, encodes a putative regulator of cholesterol and lipid metabolism. This Golgi protein turned out to play a role in the processing of SREBP, a major transcriptional regulator of cholesterol metabolism originally discovered by Brown and Goldstein. Our study also provided a clear example of how unbiased genetic methods offer an alternative means of discovering unknown components of cellular metabolism. As a junior faculty member, I found publishing this study in Nature Metabolism (E. C. Bayraktar et al. Nat. Metab. 2, 487-498; 2020) in the middle of the COVID-19 pandemic particularly motivating. It made us realize that we can still move forward in spite of major hurdles.

As a lab, we are now excited to proceed to the next stage. Several of our lab members are moving on to new postdoc positions, and others are even starting their faculty positions. Although every step of learning the ropes as a lab head brings new challenges, I have realized that mentoring and helping trainees achieve their goals is 
perhaps the most fun aspect of running a lab. I hope that, like my previous mentors, I will have the great fortune of having the same satisfaction of seeing my trainees embark on new scientific journeys.

\section{Sarah Lessard: an exercise in trial and error}

I hadn't always dreamed of having a career as a research scientist in the field of metabolism. I grew up in a small town in Northern Ontario, Canada, and the nearest university was a 2-hour drive away. I didn't know anyone with a PhD, and I wasn't exposed to academic research as a career option, as I think can be the case for many kids from rural areas. Although I was relatively isolated, I was introduced to science by my parents. My father was a high-school physics teacher, and my mother worked in a hospital as a medical laboratory technologist. We often discussed scientific topics, from weather patterns to black holes, at home. However, although both had science-related careers, my parents encouraged me to pursue a well-rounded education involving music, French and athletics, in addition to science and math. There was no expected or predetermined path that I should take.

When I applied to undergraduate programs, I was unsure of what I wanted to focus on, and I indecisively settled on an arts and science program at the University of Guelph. One of my courses in that first year focused on the history and science behind the discovery of insulin by researchers at the University of Toronto in 1921. This fascinating story, outlined in the course textbook written by historian Michael Bliss, made me realize how exciting and transformative medical research can be. As I continued through my undergraduate program, I became increasingly interested in biomedical science, which I ultimately selected as an area of emphasis for my coursework. I had excellent professors in physiology, biochemistry and anatomy, whose passion for these subjects had a lasting impact on me.

I've always had a strong personal interest in exercise and nutrition, and for my undergraduate research project, I studied the role of caffeine metabolites in delaying muscle fatigue during exercise. I was trained by Thomas Hawke, who was a graduate student at the time and is now a professor at McMaster University, to perform precise surgical dissections of mouse muscles and, to my amazement, stimulate them to contract ex vivo. This experience is what first led me to consider a career in muscle and exercise research. I decided to continue as a master's student, taking graduate

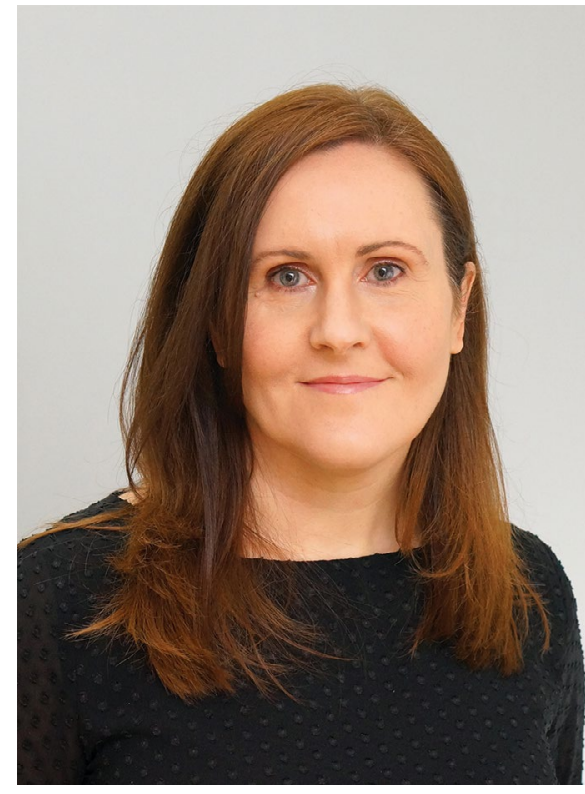

Credit: Donato Rivas

courses in exercise physiology and muscle metabolism. I enjoyed learning about the pioneering work by scientists around the globe who helped establish the exercise physiology field of today. Through my studies, I was introduced to the concept of muscle plasticity and was fascinated by the ability of this tissue to adapt its metabolism to nutritional and exercise inputs.

After completing my master's degree, I was searching for my next step, and received an e-mail advertising scholarships for international students to obtain a $\mathrm{PhD}$ in exercise and diabetes research from RMIT University in Melbourne, Australia. Although I hadn't planned to study abroad, something told me that this would be the perfect fit for me, and I decided to take the leap and pack my bags for Australia. I thought at the very least it would be a good adventure!

I learned a great deal about exercise physiology and academic science during my time in Australia, and made many lifelong friends and scientific collaborators. My $\mathrm{PhD}$ mentor, John Hawley, is a renowned figure in human exercise physiology, who introduced me to clinical research. I also had a desire to learn basic science and sought additional mentorship from other scientists, including Matthew Watt and Bruce Kemp, who were able to help me on that path. This experience taught me the value of scientific mentorship and collaboration. Establishing a multidisciplinary mentorship team in both clinical and basic science elevated the impact of my studies and allowed me to develop the translational approach that characterizes my current work.
As I prepared to embark on my final doctoral research project, using a rat model of type 2 diabetes, my plans were derailed by a catastrophic loss of rat colonies in Australia because of infection. I felt extremely discouraged by this stroke of bad luck, and we scrambled to come up with a solution. As a backup plan, I travelled to the lab of a collaborator in California to complete the project. Although it seemed like a disaster at the time, everything worked out with the project, and I finished my dissertation on time. This unplanned trip to the United States also serendipitously led me to meet my husband and continued scientific collaborator, Donato Rivas, who is now undergoing his own journey to independence as an Assistant Professor at Tufts University.

After completing my doctoral thesis, my dedication to a career in exercise and metabolism research was solidified, and I left Australia to undertake postdoctoral training at the Joslin Diabetes Center in Boston. I was fortunate to be accepted for a position in the lab of Laurie Goodyear, one of the world's foremost experts in exercise metabolism. I was inspired by the groundbreaking nature of work from the Goodyear lab and was encouraged by Goodyear's success as a female scientist in a male-dominated field. She provided guidance while simultaneously allowing me the freedom to forge my own path. This leadership style allowed me to flourish as a scientist and gain the confidence needed to consider starting my own lab. I try to emulate this mentorship style with my own trainees by giving help and advice when they need it, but encouraging them to explore new directions or methods that interest them.

For me, the process of applying for faculty positions further highlighted the importance of diverse representation in academic science. Faculty interviews often involve speaking with deans, department heads and senior faculty over the course of 2 or 3 days. In some cases, there are very few women in these leadership positions, and statistically, this underrepresentation becomes even more obvious for people of colour and other marginalized and historically underrepresented groups. My recommendation to postdocs making the transition to a faculty position is to find a department or institution with a culture of inclusivity, where you feel welcome and valued, because in my experience, this can be important to achieving your full potential as a scientist. For me, an inclusive professional culture, in policy and practice, is one in which diverse views and backgrounds are embraced and actively sought out. This is important from a social-equity standpoint, and an overwhelming amount of research has 
shown that teams with diverse backgrounds and experiences can generate better, more impactful and more innovative science.

My search for a faculty position was more difficult than I had anticipated, and despite applying for several jobs and being granted a few interviews, I didn't immediately find a good fit. I began to wonder whether I might need to explore alternative career options, when, about a year into my search, a position opened up at the Joslin Diabetes Center, where I was already working. Seemingly by fate, the position was for an assistant-professor-level exercise scientist with experience in human studies and diabetes research. I applied for the position among a talented field of applicants and, after several months of anticipation, was offered the position. This series of events reminded me of the saying that luck is what happens when preparation meets opportunity. I felt very fortunate to have found a position in which I was given a good chance to succeed, a competitive start-up package and a supportive environment. As a mentor, I try to understand the individual career goals of my trainees and develop a training plan that best prepares them to take advantage of any future opportunities that may come their way.

Despite being set up for success, my start as an independent scientist was overwhelming. Within a 1-year period, I had my son, Emmett, bought a house and started my own lab. To my surprise, this busy time helped me learn to focus on the most important tasks. My previous proclivity toward procrastination had to go and was replaced by more efficient time management. Although things still sometimes seem overwhelming, I feel I've come closer to achieving the ever-elusive 'work-life balance.' Of course, the support of family, friends, colleagues, mentors and lab members is crucial for achieving that balance. Although we can never do it all, I think we can come close enough to having both a successful career and a personal life. Some of the scientists I most admire have attained great success in their research while also taking time to pursue interests outside of their careers.

Publishing in the field of metabolism has become increasingly competitive. For new investigators, it can be hard to compete with more established scientists for spots in the top journals. Nature Metabolism has provided a much-needed platform for researchers at all career stages to share their work in a high-quality journal focused on metabolism. I was attracted to the journal because of its stated focus on exercise research and was encouraged to see articles by many of my exercise science colleagues being highlighted. The first big paper from my lab was published in Nature Metabolism in August 2020, with Tara MacDonald, a talented postdoctoral fellow, as first author (T. L. MacDonald et al. Nat. Metab. 2, 902-917; 2020). Our study identified novel signalling mechanisms that may cause impaired muscle remodelling with exercise in people and animal models with chronically elevated blood sugar. This work was inspired by decades of clinical research from leaders in exercise physiology showing that the response to exercise training is highly heterogeneous. Publication of the manuscript provided a boost to my career that sparked scientific and public interest my research program, and helped me obtain my first large-scale independent funding.

As I reflect on the path that led me here, I would like to leave you with a few tips that I found were important for achieving that first big independent paper or grant:

1. Don't be too independent. As you start your own lab, it can be tempting to try to prove your independence by not seeking out mentorship, advice and collaboration. Continued guidance from a mentorship team of senior faculty at Joslin, including Laurie Goodyear, George King and Ron Kahn, has been essential for my success as an independent scientist. They read my manuscripts and funding applications, provide ideas and advice, and make sure I have all the resources I need to succeed. It sometimes feels as if they are just as excited about my successes as I am. Likewise, establishing new collaborative relationships can expand opportunities for publication and funding. My close collaborations with scientists including Lauren Koch (University of Toledo), Steve Britton (University of Michigan) and Roger Davis (University of Massachusetts) have been key to preparing strong publications and grant applications during my first few years of independence.

2. Take a break. Although putting in many hours of hard work and focus is essential for success in any field, some of my most creative and inspired ideas have come after a brief period of rest. The first time I applied for a large independent grant, I received an especially negative review, and it was clear the project would not be funded. I wanted to jump right back into the lab to find a solution, but the news came right as I was leaving for a previously planned vacation. Near the end of the vacation, as I was walking on the beach, it became clear that I needed to take the project in a different direction. This change ultimately led to the project being funded. Stepping away from a problem-even with a short break, such as by getting some exercise-can lead to a fresh perspective.

3. Find opportunity in your failures. Inevitably, there will be experiments that fail and funding applications that get rejected. Sometimes events that seem disastrous at the time can result in good outcomes if you examine what went wrong and find a new path forward. Many of my most exciting findings have come after changing the direction of a project after a previous failure. For one of the first projects we did in my independent lab, my postdoctoral fellow and research assistant spent months treating mice with a Western diet and hours of daily exercise training, only to find that our primary outcome was unchanged by any of the treatments. As an attempt to salvage the project, we decided to use the models to test a new hypothesis instead. This is how we discovered that Western-diet treatment causes hyperactivation of JNK-SMAD signalling with exercise-a key finding from our Nature Metabolism paper.

4. Nurture your non-science skills. Knowing your field of research inside out is important. However, being a successful principal investigator involves many skills, such as communication and leadership, that can't be learned in the lab or from the scientific literature. People are often surprised when I tell them I have a terrible fear of public speaking, because this is a necessary skill for a career in science. I was fortunate to have mentors who helped me develop this skill so that I can effectively communicate my scientific findings to an audience. I spend time with my own trainees to work on their writing and public-speaking skills, and have them cultivate their leadership skills by mentoring junior trainees. Although these non-science aspects of the job might not come naturally to some, as with everything, practice makes better, if not necessarily perfect.

\section{Kivanç Birsoy $\mathbb{1 D}$ and} Sarah J. Lessard (1D)2ه

${ }^{1}$ Laboratory of Metabolic Regulation and Genetics, The Rockefeller University, New York, NY, USA. ${ }^{2} J o s$ lin Diabetes Center and Harvard Medical School, Boston, MA, USA.

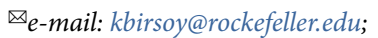
sarahlessard@joslin.harvard.edu

Published online: 7 June 2021

https://doi.org/10.1038/s42255-021-00413-8

Competing interests

The authors declare no competing interests. 